\title{
Access to pyrrolo-pyridines by gold-catalyzed hydroarylation of pyrroles tethered to terminal alkynes
}

\author{
Elena Borsini ${ }^{1}$, Gianluigi Broggini ${ }^{* 1}$, Andrea Fasana ${ }^{1}$, Chiara Baldassarri ${ }^{2}$, \\ Angelo M. Manzo ${ }^{2}$ and Alcide D. Perboni ${ }^{2}$
}

Full Research Paper

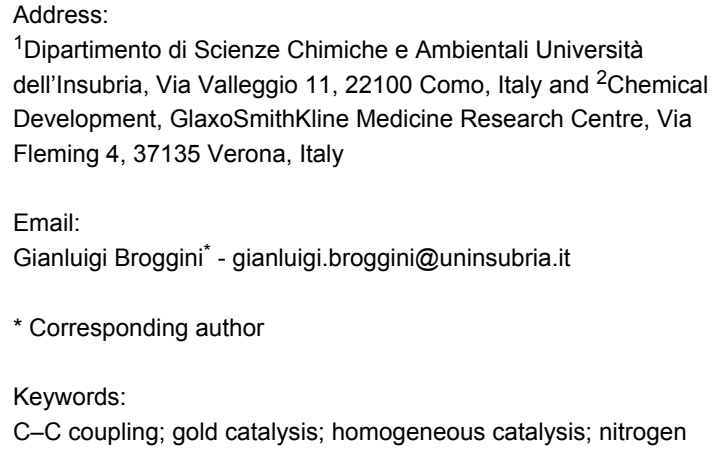

${ }^{1}$ Dipartimento di Scienze Chimiche e Ambientali Università dell'Insubria, Via Valleggio 11, 22100 Como, Italy and ${ }^{2}$ Chemical Development, GlaxoSmithKline Medicine Research Centre, Via Fleming 4, 37135 Verona, Italy

Email:

Gianluigi Broggini* - gianluigi.broggini@uninsubria.it

* Corresponding author

Keywords:

C-C coupling; gold catalysis; homogeneous catalysis; nitrogen heterocycles; rearrangement

\author{
Beilstein J. Org. Chem. 2011, 7, 1468-1474. \\ doi:10.3762/bjoc.7.170 \\ Received: 22 June 2011 \\ Accepted: 06 October 2011 \\ Published: 26 October 2011 \\ Associate Editor: J. Aubé \\ (c) 2011 Borsini et al; licensee Beilstein-Institut. \\ License and terms: see end of document.
}

\begin{abstract}
In a simple procedure, the intramolecular hydroarylation of $N$-propargyl-pyrrole-2-carboxamides was accomplished with the aid of gold(III) catalysis. The reaction led to differently substituted pyrrolo[2,3-c]pyridine and pyrrolo[3,2-c]pyridine derivatives arising either from direct cyclization or from a formal rearrangement of the carboxamide group. Terminal alkynes are essential to achieve bicyclic pyrrolo-fused pyridinones by a 6-exo-dig process, while the presence of a phenyl group at the $\mathrm{C}-\mathrm{C}$ triple bond promotes the 7-endo-dig cyclization giving pyrrolo-azepines.
\end{abstract}

\section{Introduction}

Intramolecular transition-metal-catalyzed reactions represent one of the most challenging routes for the preparation of heterocyclic compounds [1-5]. Methodologies providing heterocycles, starting from readily available substrates, by different catalytic systems, as well as selective procedures for the synthesis of different heterocycles from the same starting materials by subtle modifications of the catalytic conditions, are useful tools in the hands of organic chemists. Gold catalysis has recently emerged as a suitable way to achieve such a goal, mainly thanks to the chemoselective alkynophilic properties of this attractive metal in different types of reactions [6-15]. Among the hydroarylation reactions, various kinds of heteroaryl-substituted alkynes have been demonstrated as efficient substrates for the construction of heteropolycyclic compounds. In particular, alkynyl indoles and pyrroles were successfully used to afford $\beta$-carbolines $[16,17]$, pyrrolo-azepines [18], azepino-indoles and azocino-indoles [19] under mild conditions. 
During our studies aimed at the synthesis of complex heterocyclic systems by intramolecular transition-metal-catalyzed protocols [20-32], we reported an arylative Pd-catalyzed cyclization of $N$-allyl-pyrrole-2-carboxamides, affording pyrrolo[1,2-a]pyrazines or pyrrolo[2,3-c]pyridines (Scheme 1) [33]. The reaction provided also the isomeric pyrrolo[3,2c]pyridines arising from 1,2-migration of the amide moiety. Having recently broadened our studies toward gold catalysis $[34,35]$, we have been intrigued by the investigation of a goldcatalyzed intramolecular hydroarylation of alkynyl-tethered pyrrole-2-carboxamides in order to have an alternative protocol to access pyrrolo-fused pyridine skeletons. The importance of pyrrolo[2,3-c]pyridine and pyrrolo[3,2-c]pyridine derivatives from the biological point of view [36-50] justifies new efforts to obtain them. This study on the Au-catalyzed cyclization of $\mathrm{N}$-alkynyl-pyrrole-2-carboxamides is also focused on the effect of the alkyne substituent, as well as on the role of the solvent on the product distribution.

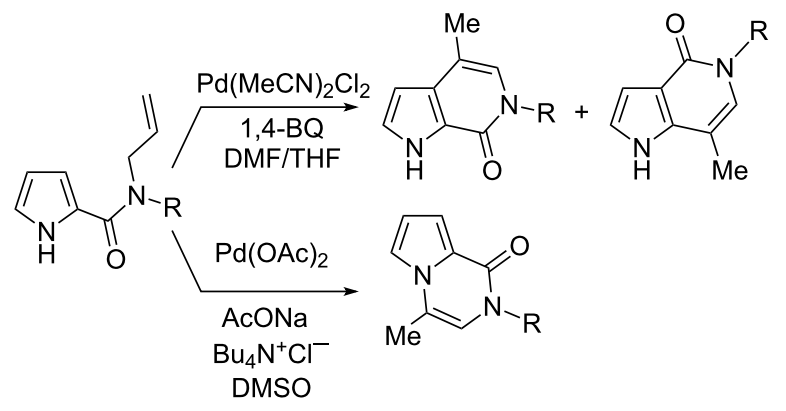

Scheme 1: Pd-catalyzed cyclization of $N$-allyl-pyrrole-2-carboxamides.

\section{Results and Discussion}

On the basis of these considerations, the $N$-propargyl amides of $1 H$-pyrrole-2-carboxylic acids $\mathbf{1 a}, \mathbf{b}$, easily prepared in high yields from the corresponding $1 H$-pyrrole-2-carboxylic acids and $N$-methyl- $N$-propargylamine with DCC as coupling reagent, were submitted to gold-catalyzed reactions under different conditions (Table 1).

First, it should be noted that the 1-unsubstituted pyrrole derivative 1a did not undergo cyclization, under various conditions, based on both $\mathrm{Au}(\mathrm{III})$ and $\mathrm{Au}(\mathrm{I})$ catalysts (Table 1, entries 1-5). Otherwise, $\mathrm{AuCl}_{3}$ was able to promote the intramolecular reaction of the methyl-substituted substrate $\mathbf{1 b}$ giving two isomeric bicyclic products. Their structures were unequivocally determined by NOESY1D, gHSQC and ${ }^{1} \mathrm{H} /{ }^{13} \mathrm{C}$ long-range correlations (gHMBC) experiments and were found to be the 6-exo-dig cyclization product $\mathbf{2 b}$ and the rearranged structure 3b (Figure 1). The best result was obtained when the reaction was performed in $\mathrm{MeCN}$ at reflux for $4 \mathrm{~h}$ (Table 1, entry 6); in this case, the ratio between $\mathbf{2} \mathbf{b}$ and $\mathbf{3} \mathbf{b}$, determined by HPLC,
Table 1: Optimization of reaction conditions.

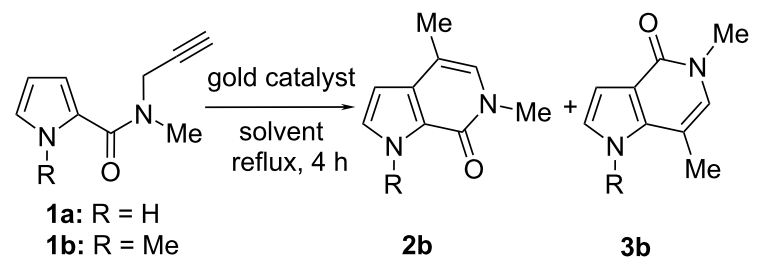

\begin{tabular}{|c|c|c|c|c|c|}
\hline Entry & Substrate & Gold catalyst ${ }^{a}$ & Solvent & $2^{b}$ & $3^{b}$ \\
\hline 1 & $1 \mathrm{a}$ & $\mathrm{AuCl}_{3}$ & $\mathrm{MeCN}$ & - & - \\
\hline 2 & $1 \mathrm{a}$ & $\mathrm{NaAuCl}_{4} \cdot 2 \mathrm{H}_{2} \mathrm{O}$ & $\mathrm{MeCN}$ & - & - \\
\hline 3 & $1 a$ & $\mathrm{AuCl}$ & DCM & - & - \\
\hline 4 & $1 \mathrm{a}$ & $\mathrm{PPh}_{3} \mathrm{AuCl} / \mathrm{AgBF}_{4}$ & $\mathrm{DCM}$ & - & - \\
\hline 5 & $1 \mathrm{a}$ & $\mathrm{AuCl}_{3}$ & $\mathrm{DCM}$ & - & - \\
\hline 6 & $1 b$ & $\mathrm{AuCl}_{3}$ & $\mathrm{MeCN}$ & 63 & 37 \\
\hline $7^{c}$ & $1 b$ & $\mathrm{NaAuCl}_{4} \cdot 2 \mathrm{H}_{2} \mathrm{O}$ & $\mathrm{MeCN}$ & 32 & 18 \\
\hline 8 & $1 b$ & $\mathrm{AuCl}$ & $\mathrm{DCM}$ & - & - \\
\hline 9 & $1 b$ & $\mathrm{PPh}_{3} \mathrm{AuCl} / \mathrm{AgBF}_{4}$ & DCM & - & - \\
\hline
\end{tabular}

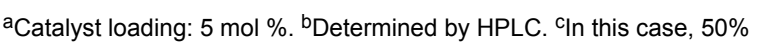
of $1 \mathrm{~b}$ was recovered.

was $1.7: 1$. The cyclization of substrate $\mathbf{1 b}$ was also accomplished by working with $\mathrm{NaAuCl}_{4} \cdot 2 \mathrm{H}_{2} \mathrm{O}$ as catalyst to give a mixture of $\mathbf{2} \mathbf{b}$ and $\mathbf{3 b}$ in the same ratio, although the conversion of the substrate was only $50 \%$ (Table 1 , entry 7). Conversely, gold(I) species were unable to promote the cyclization of substrate $\mathbf{1 b}$ (Table 1, entries 8 and 9).

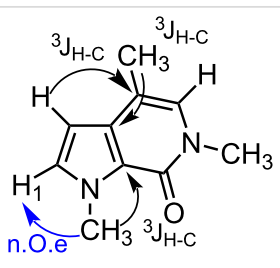

$2 \mathbf{b}$

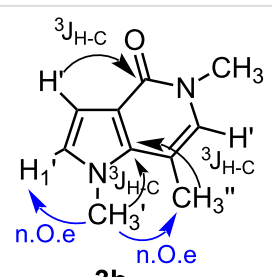

$3 \mathbf{b}$
Figure 1: Significant relationships among hydrogen and carbon atoms arising from $2 \mathrm{D}-\mathrm{NMR}$ studies to determine the pyrrolo-pyridinones.

In the presence of $\mathrm{AuCl}_{3}$, the ratio between the cyclization products $\mathbf{2 b}$ and $\mathbf{3 b}$ was significantly influenced by the solvent, as shown for the investigated conditions in Table 2. In fact, nonpolar solvents enhanced the ratio of direct to rearranged products (Table 2, entries 1 and 2), while switching to the polar ones increased the yield of $\mathbf{3 b}$ up to $50 \%$ (Table 2, entry 4). In particular, toluene and DMF were proven to be the best solvents to gain the most selective conditions ( $7: 1$ versus 1:1.6, respectively).

Other variously $N$-substituted propargylamides $(\mathbf{4 a}-\mathbf{d})$ were submitted to the $\mathrm{AuCl}_{3}$-catalyzed cyclization in different solvents. Both the isolated yields and the HPLC-MS 
Table 2: Effect of the solvent on the ratio of the isomeric products

Entry $^{\mathrm{a}}$ Solvent $T\left({ }^{\circ} \mathrm{C}\right) \quad t(\mathrm{~h}) \quad$ Ratio $^{\mathrm{b}} \quad \mathbf{2 b}^{\mathrm{c}} \quad \mathbf{3 b}^{\mathrm{c}}$

1 Toluene $\begin{array}{llllll}50 & 3 & 7: 1 & 70 & 8\end{array}$

$2 \quad$ DCM $\quad$ reflux $3 \quad 3: 1 \quad 41 \quad 16$

$3 \quad$ MeCN $\quad$ reflux $4 \quad 1.7: 1 \quad 45 \quad 30$

$4 \quad$ DMF $\quad 90 \quad 4 \quad 1: 1.6 \quad 32 \quad 50$

${ }^{\text {a }} \mathrm{AuCl}_{3}$ at $5 \mathrm{~mol} \%$. ${ }^{\text {b }} \mathrm{HPLC}-\mathrm{MS}$ ratio between peak areas. ${ }^{\mathrm{c}}$ Isolated yields after column chromatography.

isomeric ratios of direct and rearranged products are summarized in Table 3. These reactions gave rise to a varied range of products, all having pyrrolo[2,3-c]pyridinone and pyrrolo[3,2-c]pyridinone structures. Analogously to what was observed for the substrate $\mathbf{1} \mathbf{b}$, benzyl- and tosyl-substituted amides $4 \mathbf{a}$ and $\mathbf{4 b}$ afforded the expected products $\mathbf{5 a}, \mathbf{b}$ and $\mathbf{6 a}, \mathbf{b}$ Also in these cases, the ratio between the different products depends on the reaction solvent (Table 3, entries 1-7). In the case of the tert-butoxycarbonyl nitrogen-substituted substrate $4 \mathbf{c}$ the reaction gave the two exo-methylene products $7 \mathbf{c}$ and $\mathbf{8 c}$, with the product ratio being in the opposite sense for toluene compared to DCM (Table 3, entries 8 and 9). Unexpectedly, when working in acetonitrile, the sole product was compound
10 lacking the tert-butoxycarbonyl group (Table 3, entry 10). Finally, the cyclization of the benzoyl-substituted substrate $4 \mathbf{d}$ furnished only products having an internal $\mathrm{C}-\mathrm{C}$ double bond, with some products lacking the benzoyl group (Table 3, entries 11-14). The highest selectivity was obtained with toluene as solvent, where only pyrrolo[2,3-c]pyridinones, i.e., $5 \mathbf{d}$ and 9 (Table 3, entry 11), were formed.

Although the picture of the products generated from the treatment of the propargyl pyrrole-2-carboxamides with $\mathrm{AuCl}_{3}$ as catalyst is not completely homogeneous, it should be stressed that all the substrates cyclize following a 6-exo-dig process. This contrasts with the outcome of the cyclization of $N$-methyl$\mathrm{N}$-(3-arylprop-2-ynyl)-substituted 1-methyl-pyrrole-2-carboxamides in the presence of $\mathrm{AuCl}_{3}$ leading to pyrrolo-azepine derivatives, as already described in the literature by Beller and coworkers [18]. In order to shed light on the structural features determining the size of the newly formed ring, we thought it appropriate to extend this study further to $N$-propargyl-1methylpyrrole-2-carboxamides bearing a phenyl group on the acetylenic carbon. Therefore, we treated amides $11 \mathbf{a}-\mathbf{c}$ with $\mathrm{AuCl}_{3}$ as catalyst in different solvents. As given in Table 4, the reactions afforded only seven-membered cyclized products

Table 3: Scope of the reaction on differently $N$-substituted $N$-propargyl pyrrole-carboxamides.

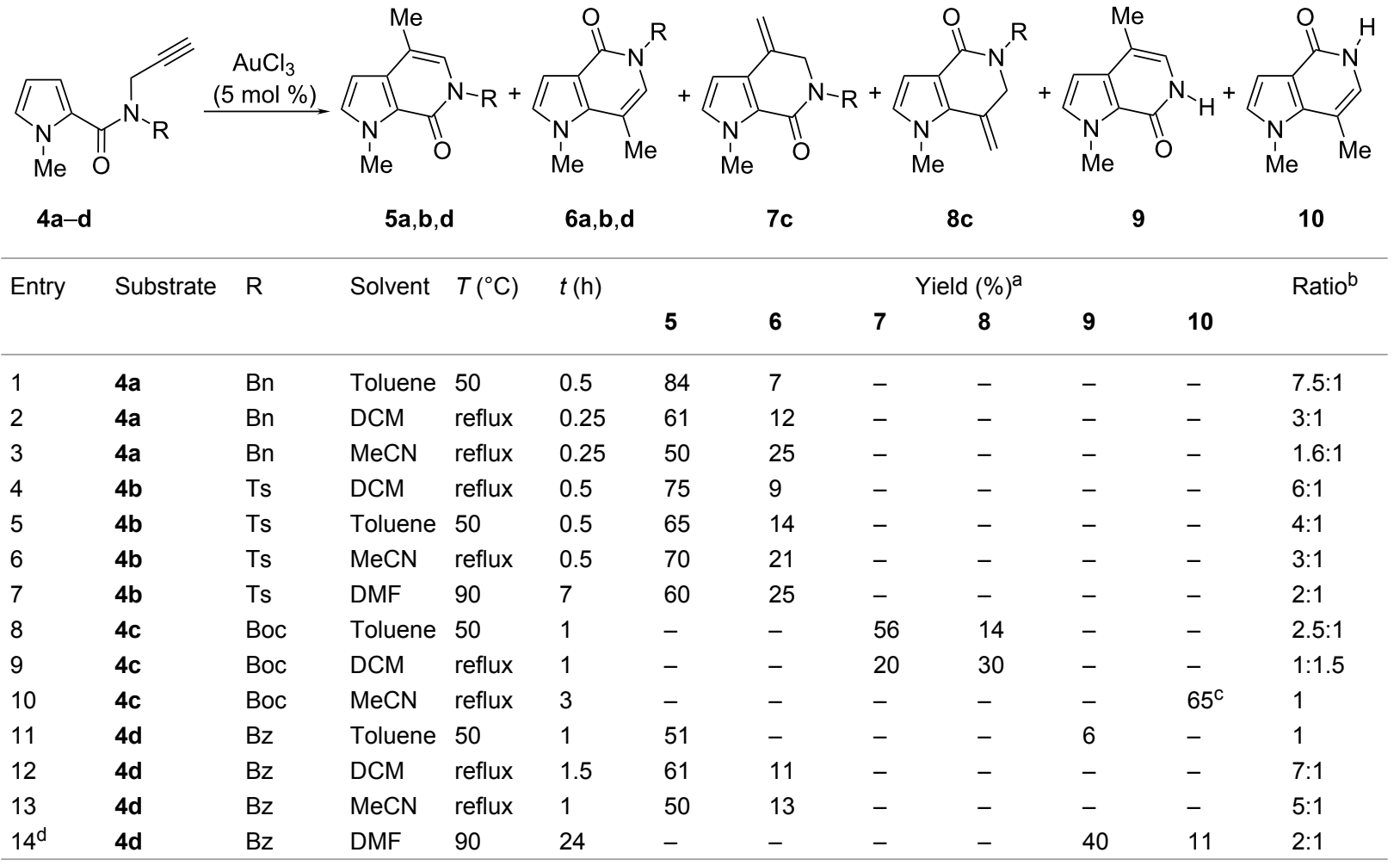


was still present. 
12a-c and 13a-c, according to Beller's work. This outcome confirmed the pivotal role of the substituent on the $\mathrm{C}-\mathrm{C}$ triple bond to direct the cyclization following 6-exo-dig or 7-endo-dig processes. Once again, the trend in terms of direct and rearranged product formation was dependent on the solvent, the 1,2-migration products being favoured in less polar solvents. The 7-endo-dig cyclizations of amides 11a-c were highly selec- tive with respect to the isomerization of the newly formed carbon-carbon double bond, since it keeps its initial position in both final structures, probably due to the conjugation with the benzene ring.

A plausible although speculative mechanism for the hydroarylation of terminal alkynes with pyrroles is shown in Scheme 2. It

Table 4: Cyclization reactions on differently $N$-substituted $N$-(3-phenyl-prop-2-ynyl) pyrrole-2-carboxamides.

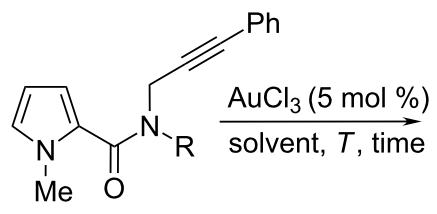

$11 \mathrm{a}-\mathrm{c}$<smiles>[R]N1CC=C(c2ccccc2)c2cn([Y6])cc2C1=O</smiles>

$13 a-c$

\begin{tabular}{|c|c|c|c|c|c|c|c|c|}
\hline \multirow[t]{2}{*}{ Entry } & \multirow[t]{2}{*}{ Substrate } & \multirow[t]{2}{*}{$\mathrm{R}$} & \multirow[t]{2}{*}{ Solvent } & \multirow[t]{2}{*}{$T\left({ }^{\circ} \mathrm{C}\right)$} & \multirow[t]{2}{*}{$t(\mathrm{~h})$} & \multirow{2}{*}{$\begin{array}{l}\text { Ratio }^{a} \\
12: 13\end{array}$} & \multicolumn{2}{|c|}{ Yield $^{b}(\%)$} \\
\hline & & & & & & & 12 & 13 \\
\hline 1 & $11 a$ & $\mathrm{Me}$ & DCM & reflux & 8 & $1: 3$ & 20 & 63 \\
\hline 2 & $11 a$ & $\mathrm{Me}$ & $\mathrm{MeCN}$ & reflux & 2 & $1.5: 1$ & 43 & 31 \\
\hline 3 & $11 a$ & $\mathrm{Me}$ & DMF & 90 & 24 & $5: 1$ & 66 & 12 \\
\hline 4 & $11 b$ & Ts & $\mathrm{DCM}$ & reflux & 0.5 & $1: 2.8$ & 20 & 60 \\
\hline 5 & $11 b$ & Ts & $\mathrm{MeCN}$ & reflux & 0.25 & $3: 1$ & 55 & 17 \\
\hline 6 & 11b & Ts & DMF & 90 & 24 & $10: 1$ & 68 & 7 \\
\hline 7 & $11 \mathrm{c}$ & $\mathrm{Bn}$ & DCM & reflux & 5 & $1: 6$ & 12 & 74 \\
\hline 8 & $11 \mathrm{c}$ & $\mathrm{Bn}$ & $\mathrm{MeCN}$ & reflux & 0.5 & $1: 2.5$ & 23 & 67 \\
\hline 9 & 11c & $\mathrm{Bn}$ & DMF & 90 & 24 & $5: 1$ & 66 & 14 \\
\hline
\end{tabular}

aHPLC-MS ratio between peak areas. ${ }^{b} /$ solated yields after column chromatography.




is highly probable that the products arise from the vinyl gold species $\mathbf{B}$ and $\mathbf{F}$, in turn generated from alkynes $\mathbf{4}$ after coordination to $\mathrm{AuCl}_{3}$. The formation of $\mathbf{F}$ can result by a migration of the acyl group from the spiro center of the transient cationic spiro gold complex $\mathbf{D}$, in turn generated by the attack of the more nucleophilic C-2 of the pyrrole nucleus on the intermediate $\mathbf{A}$. On the other hand, complex $\mathbf{B}$ can arise from the direct attack of the pyrrolic C-3 on the activated species $\mathbf{A}$ or from the migration of the alkyl group on the spiro intermediate $\mathbf{D}$. The complexes $\mathbf{B}$ and $\mathbf{F}$ evolve by protodeaurylation generating the exomethylenic compounds $\mathbf{7}$ and $\mathbf{8}$, which are eventually susceptible to alkene isomerization. The hypothesis that the alkene isomerization occurs prior to protodeaurylation, giving intermediates $\mathbf{C}$ and $\mathbf{E}$, is unlikely because the protodemetallation is generally accepted to proceed much more rapidly on vinyl gold than on alkyl gold intermediates. In all cases, the product distribution plausibly reflects their thermodynamic stability. The endocyclic alkene is favoured presumably due to the higher degree of conjugation (compounds $\mathbf{5 a}, \mathbf{b}, \mathbf{d}$ and $\mathbf{6 a}, \mathbf{b}, \mathbf{d})$, while it is reasonable to assume that the isomerization to the endocyclic alkene with the bulky $N$-BOC group (compounds $7 \mathbf{c}$ and $\mathbf{8 c}$ ) is less favourable due to the resulting strain in the planar ring.

To explain the cyclization of alkynes 11a-c, a similar mechanism could be proposed. The formation of the seven-membered cyclized products could be due to a stabilizing effect of the phenyl group in the transition state of the reaction.

\section{Conclusion}

In summary, the cyclization of $N$-alkynyl pyrrole-2-carboxamides under very mild gold-catalyzed conditions has been described. The outcome of the intramolecular hydroarylation gave 6-exo-dig or 6-endo-dig processes, depending on the substitution of the alkyne. In both cases, products arising from a direct reaction as well as products involving a 1,2-shift of the amide group were obtained, their ratio being influenced by the polarity of the solvent. The gold-catalyzed procedure to achieve pyrrolo[2,3-c]pyridines and pyrrolo[3,2-c]pyridines represents a valuable alternative to the Pd-catalyzed cyclization of the analogue allylamides.

\section{Experimental General}

Melting points were determined by capillary method with a Büchi B-540 apparatus and are uncorrected. ${ }^{1} \mathrm{H}$ and ${ }^{13} \mathrm{C}$ NMR spectra were recorded on an INOVA AS600 Variant spectrometer. ${ }^{13} \mathrm{C}$ NMR spectra are ${ }^{1} \mathrm{H}$-decoupled and the multiplicities were determined by APT pulse sequence. Chemical shifts are given as $\delta$ values in ppm relative to residual solvent peaks $\left(\mathrm{CHCl}_{3}\right)$ as the internal reference. IR spectra were measured with a Jasco FT/IR 5300 spectrometer. MS spectra were recorded on a HPLC-MS Agilent Technologies 6140 (ESI). Elemental analyses were executed on Perkin-Elmer CHN Analyzer Series II 2400. Preparative separations were performed by Biotage flash chromatography with 40M silica cartridges.

\section{Cyclization reactions of pyrrole-carboxamides}

A solution of the appropriate pyrrole-carboxamide $(2 \mathrm{mmol})$ was stirred, under an argon atmosphere, with $\mathrm{AuCl}_{3}$ $(0.01 \mathrm{mmol})$ in $30 \mathrm{~mL}$ of an appropriate solvent (see Table 3 and Table 4 for solvents, temperatures and times). At the end of the reaction, the solvent was either removed under reduced pressure (MeCN, DCM, toluene) or extracted with brine (DMF). The crude residue was purified by flash column chromatography.

\section{1,4,6-Trimethyl-1,6-dihydro-pyrrolo[2,3-c]pyridin-7- one (2b)}

Yield: $70 \%$ (Table 2, entry 1). White solid; mp $76{ }^{\circ} \mathrm{C}$; IR (nujol) v: $1670 \mathrm{~cm}^{-1} ;{ }^{1} \mathrm{H}$ NMR (599 MHz, $\left.\mathrm{CDCl}_{3}\right) \delta 2.13$ (s, $3 \mathrm{H}), 3.49$ (s, 3H), 4.13 (s, 3H), 6.17 (d, J=2.9 Hz, 1H), 6.57 (s, $1 \mathrm{H}), 6.91(\mathrm{~d}, J=2.9 \mathrm{~Hz}, 1 \mathrm{H}) ;{ }^{13} \mathrm{C} \mathrm{NMR}\left(150 \mathrm{MHz}, \mathrm{CDCl}_{3}\right) \delta$ 14.7 (q), 35.5 (q), 35.5 (q), 100.1 (d), 110.3 (s), 122.3 (s), 126.2 (d), 130.7 (d), 132.4 (s), 155.6 (s); MS m/z: $177.21\left[\mathrm{M}^{+}\right.$; Anal. calcd for $\mathrm{C}_{10} \mathrm{H}_{12} \mathrm{~N}_{2} \mathrm{O}$ : C, 68.16; H, 6.86; N, 15.90; found: $\mathrm{C}$, $68.22 ; \mathrm{H}, 6.80 ; \mathrm{N}, 15.95$.

\section{1,5,7-Trimethyl-1,6-dihydro-pyrrolo[3,2-c]pyridin-4- one (3b)}

Yield: 50\% (Table 2, entry 4). Yellow solid; mp $104{ }^{\circ} \mathrm{C}$; IR (nujol) v: $1672 \mathrm{~cm}^{-1} ;{ }^{1} \mathrm{H} \mathrm{NMR}\left(599 \mathrm{MHz}, \mathrm{CDCl}_{3}\right) \delta 2.37(\mathrm{~s}$, $3 \mathrm{H}), 3.51(\mathrm{~s}, 3 \mathrm{H}), 3.89(\mathrm{~s}, 3 \mathrm{H}), 6.65(\mathrm{~s}, 1 \mathrm{H}), 6.69(\mathrm{~d}, J=3.1 \mathrm{~Hz}$, $1 \mathrm{H}), 6.73(\mathrm{~d}, J=3.1 \mathrm{~Hz}, 1 \mathrm{H}) ;{ }^{13} \mathrm{C} \mathrm{NMR}\left(150 \mathrm{MHz}, \mathrm{CDCl}_{3}\right) \delta$ 16.1 (q), 35.8 (q), 35.8 (q), 104.4 (d), 104.5 (s), 116.9 (s), 127.4 (d), 129.8 (d), 137.9 (s), 159.6 (s); MS m/z: 177 [M] ${ }^{+}$; Anal. calcd for $\mathrm{C}_{10} \mathrm{H}_{12} \mathrm{~N}_{2} \mathrm{O}: \mathrm{C}, 68.16 ; \mathrm{H}, 6.86 ; \mathrm{N}, 15.90$; found: $\mathrm{C}$, $68.13 ; \mathrm{H}, 6.81 ; \mathrm{N}, 15.94$.

\section{1,7-Dimethyl-4-phenyl-6,7-dihydropyrrolo[2,3- c]azepin-8(1H)-one (12a)}

Yield: $66 \%$ (Table 4, entry 3). White solid; mp $118^{\circ} \mathrm{C}$; IR (nujol) v: $1673 \mathrm{~cm}^{-1} ;{ }^{1} \mathrm{H}$ NMR (599 MHz, $\left.\mathrm{CDCl}_{3}\right) \delta 3.17(\mathrm{~s}$, $3 \mathrm{H}), 3.78(\mathrm{~d}, J=6.9 \mathrm{~Hz}, 2 \mathrm{H}), 4.00(\mathrm{~s}, 3 \mathrm{H}), 5.95(\mathrm{~d}, J=2.8 \mathrm{~Hz}$, $1 \mathrm{H}), 6.07(\mathrm{t}, J=6.9 \mathrm{~Hz}, 1 \mathrm{H}), 6.73(\mathrm{~d}, J=2.8 \mathrm{~Hz}, 1 \mathrm{H})$, 7.33-7.37 (m, 3H), 7.38-7.40 (m, 2H); ${ }^{13} \mathrm{C}$ NMR (150 MHz, $\left.\mathrm{CDCl}_{3}\right) \delta 34.6$ (q), 36.6 (q), 47.5 (t), 107.7 (d), 119.6 (d), 126.6 (s), 126.7 (d), 127.1 (s), 127.7 (d), 128.1 (d), 128.5 (d), 140.5 (s), $142.6(\mathrm{~s}), 162.2(\mathrm{~s})$; MS m/z: $253[\mathrm{M}]^{+}$; Anal. calcd for $\mathrm{C}_{16} \mathrm{H}_{16} \mathrm{~N}_{2} \mathrm{O}$ : C, 76.16; $\mathrm{H}, 6.39$; N, 11.10; found: $\mathrm{C}, 76.24 ; \mathrm{H}$, $6.35 ; \mathrm{N}, 11.04$. 


\section{1,5-Dimethyl-8-phenyl-5,6-dihydropyrrolo[3,2- c]azepin-4(1H)-one (13a)}

Yield: $63 \%$ (Table 4, entry 1). White solid; mp $130{ }^{\circ} \mathrm{C}$; IR (nujol) v: $1676 \mathrm{~cm}^{-1} ;{ }^{1} \mathrm{H}$ NMR $\left(599 \mathrm{MHz}, \mathrm{CDCl}_{3}\right) \delta 3.07$ (s, $3 \mathrm{H}), 3.17$ (s, 3H), $3.74(\mathrm{~d}, J=7.2 \mathrm{~Hz}, 2 \mathrm{H}), 6.13(\mathrm{t}, J=7.2 \mathrm{~Hz}$, $1 \mathrm{H}), 6.63(\mathrm{~d}, J=2.8 \mathrm{~Hz}, 1 \mathrm{H}), 6.77(\mathrm{~d}, J=2.8 \mathrm{~Hz}, 1 \mathrm{H}), 7.22(\mathrm{~d}$, $J=6.4 \mathrm{~Hz}, 2 \mathrm{H}), 7.32-7.35(\mathrm{~m}, 3 \mathrm{H}) ;{ }^{13} \mathrm{C} \mathrm{NMR}(150 \mathrm{MHz}$, $\left.\mathrm{CDCl}_{3}\right) \delta 35.3(\mathrm{q}), 36.4(\mathrm{q}), 47.5(\mathrm{t}), 109.6(\mathrm{~d}), 123.2(\mathrm{~s}), 124.3$ (d), 124.7 (d), 127.5 (d), 128.0 (d), 128.6 (d), 131.5 (s), 137.8 (s), $139.3(\mathrm{~s}), 166.0(\mathrm{~s}) ; \mathrm{MS} \mathrm{m} / z: 253[\mathrm{M}]^{+}$; Anal. calcd for $\mathrm{C}_{16} \mathrm{H}_{16} \mathrm{~N}_{2} \mathrm{O}: \mathrm{C}, 76.16 ; \mathrm{H}, 6.39 ; \mathrm{N}, 11.10$; found: $\mathrm{C}, 76.23$; $\mathrm{H}$, $6.30 ; \mathrm{N}, 11.04$.

\section{Supporting Information}

\section{Supporting Information File 1}

Experimental procedures and characterization data. [http://www.beilstein-journals.org/bjoc/content/ supplementary/1860-5397-7-170-S1.pdf]

\section{Acknowledgements}

The authors thank the Ministero dell'Università e della Ricerca for financial support (PRIN 2008KRBX3B) and Stefano Provera for helpful discussions.

\section{References}

1. Nakamura, I.; Yamamoto, Y. Chem. Rev. 2004, 104, 2127-2198. doi:10.1021/cr020095i

2. Li, J. J.; Gribble, G. W. Palladium in Heterocyclic Chemistry. A Guide for the Synthetic Chemist; Pergamon: New York, 2000.

3. Godoi, B.; Schumacher, R. F.; Zeni, G. Chem. Rev. 2011, 111, 2937-2980. doi:10.1021/cr100214d

4. Beccalli, E. M.; Broggini, G.; Fasana, A.; Rigamonti, M. J. Organomet. Chem. 2011, 696, 277-295. doi:10.1016/j.jorganchem.2010.09.078

5. Patil, N. T.; Yamamoto, Y. Chem. Rev. 2011, 111, 3395-3442. doi:10.1021/cr050041j

6. Shen, H. C. Tetrahedron 2008, 64, 3885-3903. doi:10.1016/j.tet.2008.01.081

7. Shen, H. C. Tetrahedron 2008, 64, 7847-7870. doi:10.1016/j.tet.2008.05.082

8. Jiménez-Núñez, E.; Echavarren, A. M. Chem. Rev. 2008, 108, 3326-3350. doi:10.1021/cr0684319

9. Arcadi, A. Chem. Rev. 2008, 108, 3266-3325. doi:10.1021/cr068435d

10. Marion, N.; Nolan, S. P. Chem. Soc. Rev. 2008, 37, 1776-1782. doi:10.1039/b711132k

11. Fürstner, A. Chem. Soc. Rev. 2009, 38, 3208-3221. doi:10.1039/b816696j

12. Shapiro, N. D.; Toste, F. D. Synlett 2010, 675-691. doi:10.1055/s-0029-1219369

13. Corma, A.; Leyva-Pérez, A.; Sabater, M. J. Chem. Rev. 2011, 111, 1657-1712. doi:10.1021/cr100414u

14. Krause, N.; Winter, C. Chem. Rev. 2011, 111, 1994-2009. doi:10.1021/cr1004088
15. Bandini, M. Chem. Soc. Rev. 2011, 40, 1358-1367. doi:10.1039/c0cs00041h

16. England, D. B.; Padwa, A. Org. Lett. 2008, 10, 3631-3634. doi:10.1021/ol801385h

17. Verniest, G.; England, D.; De Kimpe, N.; Padwa, A. Tetrahedron 2010, 66, 1496-1502. doi:10.1016/j.tet.2009.10.033

18. Gruit, M. M.; Michalik, D.; Krüger, K.; Spannenberg, A.; Tillack, A.; Pews-Davtyan, A.; Beller, M. Tetrahedron 2010, 66, 3341-3352. doi:10.1016/j.tet.2010.02.091

19. Ferrer, C.; Echavarren, A. M. Angew. Chem., Int. Ed. 2006, 45, 1105-1109. doi:10.1002/anie.200503484

20. Broggini, G.; Molteni, G.; Terraneo, A.; Zecchi, G. Heterocycles 2003, 59, 823-858. doi:10.3987/REV-02-SR5

21. Beccalli, E. M.; Broggini, G.; Martinelli, M.; Paladino, G.; Zoni, C. Eur. J. Org. Chem. 2005, 2091-2096. doi:10.1002/ejoc.200400817

22. Abbiati, G.; Beccalli, E. M.; Broggini, G.; Paladino, G.; Rossi, E. Synthesis 2005, 2881-2886. doi:10.1055/s-2005-916033

23. Abbiati, G.; Beccalli, E. M.; Broggini, G.; Martinelli, M.; Paladino, G. Synlett 2006, 73-76. doi:10.1055/s-2005-922788

24. Beccalli, E. M.; Broggini, G.; Martinelli, M.; Masciocchi, N.; Sottocornola, S. Org. Lett. 2006, 8, 4521-4524. doi:10.1021/ol061693c

25. Beccalli, E. M.; Borsini, E.; Broggini, G.; Rigamonti, M.; Sottocornola, S. Synlett 2008, 1053-1057. doi:10.1055/s-2008-1072583

26. Beccalli, E. M.; Broggini, G.; Clerici, F.; Galli, S.; Kammerer, C.; Rigamonti, M.; Sottocornola, S. Org. Lett. 2009, 11, 1563-1566. doi:10.1021/ol900171g

27. Basolo, L.; Beccalli, E. M.; Borsini, E.; Broggini, G. Tetrahedron 2009, 65, 3486-3491. doi:10.1016/j.tet.2009.02.025

28. Beccalli, E. M.; Borsini, E.; Brenna, S.; Galli, S.; Rigamonti, M.; Broggini, G. Chem.-Eur. J. 2010, 16, 1670-1678. doi:10.1002/chem.200902071

29. Beccalli, E. M.; Bernasconi, A.; Borsini, E.; Broggini, G.; Rigamonti, M.; Zecchi, G. J. Org. Chem. 2010, 75, 6923-6932. doi:10.1021/jo101501u

30. Broggini, G.; Beccalli, E. M.; Borsini, E.; Fasana, A.; Zecchi, G. Synlett 2011, 227-230. doi:10.1055/s-0030-1259295

31. Borsini, E.; Broggini, G.; Colombo, F.; Khansaa, M.; Fasana, A.; Galli, S.; Passarella, D.; Riva, E.; Riva, S. Tetrahedron: Asymmetry 2011, 22, 264-269. doi:10.1016/j.tetasy.2011.01.008

32. Borsini, E.; Broggini, G.; Fasana, A.; Galli, S.; Khansaa, M.; Piarulli, U.; Rigamonti, M. Adv. Synth. Catal. 2011, 353, 985-994. doi:10.1002/adsc.201000889

33. Beccalli, E. M.; Broggini, G.; Martinelli, M.; Paladino, G. Tetrahedron 2005, 61, 1077-1082. doi:10.1016/j.tet.2004.11.066

34. Manzo, A. M.; Perboni, A. D.; Broggini, G.; Rigamonti, M. Tetrahedron Lett. 2009, 50, 4696-4699. doi:10.1016/j.tetlet.2009.06.011

35. Manzo, A. M.; Perboni, A. D.; Broggini, G.; Rigamonti, M. Synthesis 2011, 127-132. doi:10.1055/s-0030-1258346

36. Chezal, J.-M.; Paeshuyse, J.; Gaumet, V.; Canitron, D.; Maisonial, A.; Lartigue, C.; Gueiffier, A.; Moreau, E.; Teulade, J.-C.; Chavignon, O.; Neyts, J. Eur. J. Med. Chem. 2010, 45, 2044-2047. doi:10.1016/j.ejmech.2010.01.023

37. Sahoo, S. P.; Chen, M.-H.; Dykstra, K. D.; Koyama, H.; Meinke, P. T.; O'Keefe, S. J.; Yang, G. X.-Q. Pyrrolo [2,3-c] pyridine derivatives as P38 kinase inhibiting agents. PCT Patent WO2009/152072 A1, Dec 17, 2009. 
38. Giblin, G. M. P.; Billinton, A.; Briggs, M.; Brown, A. J.; Chessell, I. P.; Clayton, N. M.; Eatherton, A. J.; Goldsmith, P.; Haslam, C.; Johnson, M. R.; Mitchell, W. L.; Naylor, A.; Perboni, A.; Slingsby, B. P.; Wilson, A. W. J. Med. Chem. 2009, 52, 5785-5788. doi:10.1021/jm9009857

39. Vanotti, E.; Amici, R. R.; Bargiotti, A.; Berthelsen, J.; Bosotti, R.; Ciavolella, A.; Cirla, A.; Cristiani, C.; D’Alessio, R.; Forte, B.; Isacchi, A.; Martina, K.; Menichincheri, M.; Molinari, A.; Montagnoli, A.; Orsini, P.; Pillan, A.; Roletto, F.; Scolaro, A.; Tibolla, M.; Valsasina, B.; Varasi, M.; Volpi, D.; Santocanale, C. J. Med. Chem. 2008, 51, 487-501. doi:10.1021/jm700956r

40. Cheng, L.; Helgesson, S. A. Therapeutic Agents. PCT Patent WO2008/119999 A1, Oct 9, 2008.

41. Ni, F.; Kota, S.; Takahashi, V.; Strosberg, A. D.; Snyder, J. K. Bioorg. Med. Chem. Lett. 2011, 21, 2198-2202. doi:10.1016/j.bmcl.2011.03.014

42. Vintonyak, V. V.; Waldmann, H.; Rauh, D. Bioorg. Med. Chem. 2011, 19, 2145-2155. doi:10.1016/j.bmc.2011.02.047

43. Li, G.-B.; Yang, L.-L.; Feng, S.; Zhou, J.-P.; Huang, Q.; Xie, H.-Z.; Li, L.-L.; Yang, S.-Y. Bioorg. Med. Chem. Lett. 2011, 21, 1736-1740. doi:10.1016/j.bmcl.2011.01.087

44. Chen, J.; Liu, T.; Wu, R.; Lou, J.; Dong, X.; He, Q.; Yang, B.; Hu, Y. Eur. J. Med. Chem. 2011, 46, 1343-1347. doi:10.1016/j.ejmech.2011.01.057

45. Martini, E.; Mannelli, L. C.; Bartolucci, G.; Bertucci, C.; Dei, S.; Ghelardini, C.; Guandalini, L.; Manetti, D.; Scapecchi, S.; Teodori, E.; Romanelli, M. N. J. Med. Chem. 2011, 54, 2512-2516. doi:10.1021/jm101376k

46. Simard, D.; Leblanc, Y.; Berthelette, C.; Zaghdane, M. H.; Molinaro, C.; Wang, Z.; Gallant, M.; Lau, S.; Thao, T.; Hamel, M.; Stocco, R.; Sawyer, N.; Sillaots, S.; Gervais, F.; Houle, R.; Lévesque, J.-F. Bioorg. Med. Chem. Lett. 2011, 21, 841-845. doi:10.1016/j.bmcl.2010.11.084

47. Johnson, T. W.; Tanis, S. P.; Butler, S. L.; Dalvie, D.; DeLisle, D. M.; Dress, K. R.; Flahive, E. J.; Hu, Q.; Kuehler, J. E.; Kuki, A.; Liu, W.; McClellan, G. A.; Peng, Q.; Plewe, M. B.; Richardson, P. F.; Smith, G. L.; Solowiej, J.; Tran, K. T.; Wang, H.; Yu, X.; Zhang, J.; Zhu, H. J. Med. Chem. 2011, 54, 3393-3417. doi:10.1021/jm200208d

48. Bi, W.; Bi, Y.; Xue, P.; Zhang, Y.; Gao, X.; Wang, Z.; Li, M.; Baudy-Floc'h, M.; Ngerebara, N.; Gibson, M. K.; Bi, L. Eur. J. Med. Chem. 2011, 46, 1453-1462. doi:10.1016/j.ejmech.2011.01.021

49. Yang, M.-L.; Kuo, P.-C.; Hwang, T.-L.; Chiou, W.-F.; Qian, K.; Lai, C.-Y.; Lee, K.-H.; Wu, T.-S. Bioorg. Med. Chem. 2011, 19, 1674-1682. doi:10.1016/j.bmc.2011.01.034

50. Duan, J.-X.; Cai, X.; Meng, F.; Sun, J. D.; Liu, Q.; Jung, D.; Jiao, H.; Matteucci, J.; Jung, B.; Bhupathi, D.; Ahluwalia, D.; Huang, H.; Hart, C. P.; Matteucci, M. J. Med. Chem. 2011, 54, 1715-1723. doi:10.1021/jm101354u

\section{License and Terms}

This is an Open Access article under the terms of the Creative Commons Attribution License

(http://creativecommons.org/licenses/by/2.0), which permits unrestricted use, distribution, and reproduction in any medium, provided the original work is properly cited.

The license is subject to the Beilstein Journal of Organic Chemistry terms and conditions:

(http://www.beilstein-journals.org/bjoc)

The definitive version of this article is the electronic one which can be found at:

doi:10.3762/bjoc.7.170 